\title{
Manifestações patológicas oriundas da falta de estanqueidade em pavilhão de laboratórios de uma instituição de ensino pública
}

\author{
L. Cardoso Gabriel ${ }^{1 *}$, W. da Silva Pereira ${ }^{2}$, A. Cruz Passuello ${ }^{3}$ \\ *Autor de Contacto: eng.larissagabriel@gmail.com \\ ${ }^{1}$ Engenheira Civil, Universidade Federal do Recôncavo da Bahia, Cruz das Almas - BA, Brasil \\ ${ }^{2}$ Engenheiro Civil. Docente da Faculdade FACTIVA, Valença - BA, Brasil \\ ${ }^{3}$ Doutora em Engenharia Civil pela Università Politécnica delle Marche. Docente da Universidade Federal do \\ Recôncavo da Bahia, Cruz das Almas - BA, Brasil \\ ${ }^{1,2,3}$ Grupo de Pesquisa para Preservação e Ocupação Seguro do Ambiente Construído (GP-POSAC)
}

\begin{abstract}
RESUMO
O presente trabalho tem como objetivo realizar um levantamento de manifestações patológicas oriundas de umidade descendente verificando o possível comprometimento da estanqueidade em um dos pavilhões de laboratórios de uma instituição de ensino federal. Para a identificação e classificação das manifestações patológicas utilizou-se o método de Lichtenstein e a norma de inspeção do Instituto Brasileiro de Avaliações e Perícias de Engenharia - IBAPE. Foram realizadas inspeções visuais na cobertura, fachada e interior da edificação, levantando ocorrências, localizações, classificando as manifestações patológicas, seus graus de risco e possíveis causas. As causas prováveis identificadas foram ligadas à utilização inadequada da impermeabilização, vedação das paredes, erros de execução e a falta de manutenção.
\end{abstract}

Palavras-chave: Manifestações Patológicas; Inspeção; Estanqueidade; Umidade Descendente.

\section{Pathological manifestations arising from the lack of watertightness in the laboratory pavilion of a public educational institution}




\begin{abstract}
The objective of this work aims to carry out a survey of pathological manifestations arising from descending humidity, verifying the possible impairment of watertightness in one of the laboratory pavilions of a federal educational institution. For the identification and classification of pathological manifestations, the Lichtenstein method and the inspection standard of the Brazilian Institute of Engineering Assessments and Expertise - IBAPE. Visual inspections were carried out on the building's roof, facade and interior, surveying occurrences, locations, classifying pathological manifestations, their degrees of risk and possible causes. The probable causes identified were linked to the improper use of waterproofing, wall sealing, execution errors and the lack of maintenance.
\end{abstract}

Keywords: Pathological Manifestations; Inspection; Watertightness; Descending Humidity.

\title{
Manifestaciones patológicas derivadas de la falta de estanqueidad en el pabellón del laboratorio de una institución educativa federal.
}

\section{RESUMEN}

El presente trabajo tiene como objetivo realizar un relevamiento de las manifestaciones patológicas derivadas del descenso de la humedad, comprobando la posible alteración de la estanqueidad en uno de los pabellones de laboratorio de una institución educativa federal. Para la identificación y clasificación de las manifestaciones patológicas se utilizó el método de Lichtenstein y el estándar de inspección del Instituto Brasileño de Evaluación y Pericia en Ingeniería - IBAPE. Se realizaron inspecciones visuales en la cubierta, fachada e interior del edificio, identificando ocurrencias, ubicaciones, clasificando las manifestaciones patológicas, sus grados de riesgo y posibles causas. Las causas probables identificadas estuvieron vinculadas al uso inadecuado de impermeabilizaciones, sellado de muros, errores de ejecución y falta de mantenimiento.

Palabras clave: Manifestaciones patológicas; Inspección; Estanqueidad; Humedad descendente.

\section{INTRODUÇÃO}

O desempenho que uma edificação apresentará durante a sua vida útil está condicionado a decisões e ações realizadas ao longo de todas as etapas que envolvem o seu processo executivo. A concepção 
inadequada de uma edificação, o projeto deficiente e a execução sem qualidade conduzirão a problemas patológicos que poderão requerer ações de manutenção corretiva não esperadas, extremamente precoces e, em grande parte dos casos, com custos excessivos.

Anomalias decorrentes de falhas nas especificações projetivas e falhas construtivas podem permitir o acesso de agentes causadores de deterioração dos elementos construtivos, podendo comprometer inicialmente as questões relacionadas a habitabilidade da edificação, mas também, posteriormente, conduzir a processos patológicos mais severos, que poderão comprometer a integridade estrutural da construção. A presença de umidade constante nas edificações é um agente deletério importante e causa uma série de inconvenientes aos usuários, sendo motivo do desencadeamento de inúmeras manifestações patológicas. Problemas de umidade interna nas edificações podem ser gerados por decisões errôneas no projeto, mas principalmente por falhas na etapa de execução que permitirão o acesso da água por umidade ascensional, ou então, devido à falta de estanqueidade em relação a cobertura ou elementos de vedação. Além disso, uma programação ineficiente ou inexistente de manutenção poderá conduzir ao início do problema, mas principalmente acelerar o processo de degradação quando não ocorrer a solução imediata do problema que está conduzindo a falta de estanqueidade.

Este trabalho busca realizar um levantamento de manifestações patológicas oriundas de umidade descendente verificando o possível comprometimento da estanqueidade em um dos pavilhões de laboratórios de uma instituição de ensino federal, cuja construção foi finalizada em 2013. A edificação está localizada no município de Cruz das Almas, Bahia, Brasil e abriga, entre outros espaços, 27 laboratórios dos cursos de engenharias.

\section{REFERENCIAL TEÓRICO}

\subsection{Desempenho das edificações}

Segundo a Norma Regulamentadora Brasileira - NBR 15575, o desempenho de uma edificação é definido como o comportamento em uso de um edifício e seus sistemas (fundação, estrutura, piso, vedações, cobertura etc.), considerando as funções específicas no qual ele foi projetado (ABNT, 2013). A avaliação deste desempenho ocorrerá com base na avaliação de critérios estabelecidos a partir das exigências dos usuários relativas à segurança, a habitabilidade e a sustentabilidade.

As exigências de segurança visam a proteção do usuário da edificação, frente a integridade estrutural, a ocorrência e propagação de incêndios, bem como pela segurança de uso e operação dos próprios componentes que integram a construção. A habitabilidade pode ser entendida como o conjunto de aspectos que interferem na qualidade de vida e comodidade dos usuários, considerando a satisfação de suas necessidades físicas, psicológicas e socioculturais. Levando em consideração esse conceito, é possível associar a habitabilidade como conforto associado a questões térmicas, acústicas, táctil, de luminosidade, estanqueidade, segurança, salubridade e demais quesitos envolvidos na fruição e construção do espaço construído (ABNT, 2013). Por fim, em termos de requisitos de sustentabilidade, os critérios de análise de desempenho focam na durabilidade e manutenibilidade da edificação como um todo. A durabilidade do edifício e seus sistemas é comprometida quando o elemento passa a não atender as funções para qual foi projetado (ABNT, 2013).

O intervalo de tempo entre o início do uso e o momento em que o desempenho mínimo estabelecido em projeto passa a ser comprometido, é denominado de vida útil. Esse período de vida útil é caracterizado pelas influências no valor teórico determinado em projeto (vida útil de projeto), seja por fatores internos em que os usuários podem controlar como manutenção e intempéries ou então, por fatores externos como ações da natureza em que não é possível o controle. Já a manutenibilidade das construções está associada a facilidade de manutenção dos elementos 
construtivos, a fim de favorecer as inspeções prediais e possíveis intervenções que devem estar previstas no manual de uso, operação e manutenção da edificação (ABNT, 2013).

\subsection{Patologia das construções}

Entende-se como mecanismos de deterioração das estruturas os processos que levam a queda de desempenho dos elementos e sistemas que compõem as edificações. A área da ciência que se ocupa justamente do estudo das origens, formas de manifestação, consequências e mecanismos que levam a ocorrência de falhas e degradação das estruturas é denominada Patologia das Construções (Souza e Ripper, 1998).

De acordo com Souza e Ripper (1998) é extremamente importante conhecer as origens da deterioração, não apenas para a aplicação de terapias como também para que os problemas não retornem. Na área da patologia das construções, utiliza-se o termo manifestações patológicas para designar os sintomas dos processos de deterioração das edificações. Estes sintomas sofrem influência devido as características físicas, químicas ou mecânicas dos materiais, podendo ocorrer nas áreas internas ou externas, dependendo do uso, alterando o comportamento das construções e refletindo diretamente em seu desempenho.

O processo de construção de uma edificação é constituído de etapas que incluem o planejamento, o projeto, a escolha de materiais, a execução propriamente dita, bem como o seu uso ao longo do tempo. Sendo assim, a causa dos problemas patológicos das edificações pode ser gerada a partir de quaisquer dessas etapas (Costa Junior e Silva, 2003). Segundo Pina (2013), os tipos de manifestações patológicas mais comuns nas construções, que podem representar riscos à segurança dos usuários, são corrosão de armaduras, trincas, fissuras, rachaduras, degradação do concreto, manchas, descolamento de revestimento e infiltração, onde esta última pode vir a ser a causa do desencadeamento de todas as anteriores.

\subsection{Manifestações patológicas devido a umidade descendente}

A umidade se comporta como facilitador do desenvolvimento da maioria dos processos de deterioração das edificações, cujos sintomas se apresentarão sob a forma de manifestações patológicas. Podem ter diferentes proveniências nas edificações, derivando tanto da exposição a uma atmosfera úmida como também pelo contato direto da sua superfície com a água líquida. De acordo com Bertoline (2010), a origem da umidade nas edificações pode ocorrer através de quatro (4) situações distintas: umidade por elevação, umidade por vapor, umidade descendente (ou de precipitação) e umidade da construção.

A umidade proveniente da água pluvial é a umidade com origem descendente, que pode ser provocada pela ação direta da água da chuva nas paredes das edificações ou, então, por infiltração devido a ineficiência de alguma parte construtiva, tais como cobertura, calhas, fissuras no reboco, sistema de impermeabilização, etc (Bertoline, 2010). Algumas formas de presença da umidade podem ser detectadas a partir de manifestações patológicas como manchas, mofo, descascamento, descolamentos, eflorescência, fissuras, trincas, entre outras. Elas podem surgir tanto em elementos de vedação, como as alvenarias, quanto na estrutura como as de concreto armado (Cechinel et al., 2007).

Para a proteção das edificações contra a presença de umidade são utilizados sistemas como cobertura, sistema pluvial, impermeabilização, entre outros. Estes artifícios precisam garantir a estanqueidade à edificação e quando não são executados de forma correta surgem as manifestações patológicas.

O sistema pluvial de uma edificação tem como objetivo conduzir a água proveniente das chuvas. De acordo com a NBR 10844, em instalações prediais de águas pluviais as instalações devem obedecer aos critérios como: estanqueidade, limpeza fácil, suportar variações térmicas, resistir às intempéries, entre outros (ABNT, 1989). Manifestações patológicas como manchas em forros e 
paredes, goteiras e mofo devido a ação da umidade descendente podem ocorrer por diversos fatores, tais como: soldas incompletas ou rompidas em telhas e calhas, caimento de água falho, calhas instaladas de maneira errada, fixação insuficiente dos rufos, entupimento por falta de manutenção, falta ou falha de impermeabilização entre outros (Souza, 2008).

Segundo Yazigi (2009) existe uma diversidade de sistemas de impermeabilização, alguns desses sistemas podem ser de membranas flexíveis moldadas in loco como emulsões asfálticas, mantas flexíveis pré-fabricadas como as mantas asfálticas e membranas rígidas moldadas in loco como a argamassa rígida. Sistemas rígidos são indicados para elementos de pouca movimentação e que não serão expostos a variações térmicas e exposição à radiação solar, já os sistemas flexíveis são para elementos que são expostos e sofrem movimentação. A escolha de um sistema de impermeabilização ideal varia de acordo com a necessidade da edificação, sendo analisados fatores como custo, tipo de estrutura a ser aplicada, vida útil, tamanho da obra etc.

A ausência de projetos de impermeabilização intensifica a frequência de insucessos na estanqueidade de uma construção. Deve-se os insucessos da impermeabilização principalmente a inexistência do Projeto de Impermeabilização, a desqualificação da mão de obra, a utilização de materiais fora da norma, influência dos projetos arquitetônico e estrutural na impermeabilização, entre outros (Soares, 2014).

\section{MÉTODO}

\subsection{Método da pesquisa}

Para a atingir os objetivos propostos nesta pesquisa foi realizado um estudo de caso no Pavilhão de Laboratórios de uma instituição pública localizada no município de Cruz das Almas, Bahia, Brasil, por meio de inspeções do local, identificando as manifestações patológicas causadas apela entrada de água pluvial. A inspeção foi realizada através de registros fotográficos da cobertura, fachada e interior da edificação, quantificando as manifestações, avaliando a ocorrência nos elementos construtivos e suas localizações, além de classificá-las de acordo com o grau de risco.

Este trabalho se delimitou apenas às inspeções visuais, não sendo realizados exames complementares como ensaios laboratoriais ou na estrutura (destrutivos ou não). Foi realizada uma reflexão sobre os tipos de sintomas presentes, suas possíveis causas e graus de riscos associados. A edificação escolhida foi construída em 2013, sendo escolhida justamente devido à pouca idade da edificação (considerando a data da inspeção) e por apresentar um número expressivo de manifestações patológicas que estão comprometendo seu desempenho.

Para a identificação das manifestações patológicas foi utilizado o método de Lichtenstein (1986), no que se refere aos conceitos de levantamento de subsídios e o diagnóstico da situação. $O$ levantamento de subsídios é a etapa onde são obtidas as informações essenciais para o entendimento das manifestações patológicas que podem ser obtidas através de vistoria do local, levantamento do histórico e resultado de análises. O levantamento de subsídios também incluiu os projetos arquitetônicos e estruturais fornecidos pela instituição. O diagnóstico da situação é o entendimento dos fenômenos avaliando as possíveis causas e efeitos das manifestações patológicas na vida útil da estrutura. Neste estudo foi realizado a partir da delimitação quanto a presença da umidade descendente (precipitação) e identificação dos indícios da falha de estanqueidade da estrutura.

Os ambientes foram vistoriados isoladamente e o levantamento das manifestações patológicas seguiu os requisitos mínimos da Norma Nacional de Inspeção do IBAPE (IBAPE, 2012). As inspeções foram realizadas em três momentos distintos com o objetivo de analisar o comportamento da edificação frente a estanqueidade. A primeira inspeção foi realizada na fachada e cobertura, no dia 31 de maio de 2019, após precipitações pluviométricas. A segunda inspeção foi 
realizada na parte interna da edificação em um período anterior às constantes chuvas, no dia 3 de junho de 2019. Já a terceira inspeção foi realizada no dia 12 de junho de 2019 após períodos de chuvas, tornando possível a avaliação de quais foram as áreas mais afetadas.

O registro fotográfico das áreas internas foi realizado por uma câmera fotográfica com 20.3 megapixel. A fachada e cobertura foram inspecionadas a partir do registro fotográfico e vídeo de dois drones um com uma câmera de bordo equipada com um sensor CMOS de 20 megapixels de 1" e outro com uma câmera equipada com um sensor CMOS de 1/2.3" de 12 megapixels acopladas. O tratamento das informações coletadas ocorreu através da divisão das manifestações patológicas em grupos, quais sejam: manchas e mofo, descascamento, descolamento, eflorescência, fissuras e trincas, corrosão das armaduras e corrosão da estrutura metálica. Para cada grupo de manifestação foram identificados os elementos construtivos e sua localização no Pavilhão de Engenharias. A localização foi analisada contabilizando a ocorrência nas diferentes regiões da edificação. As ocorrências foram correlacionadas com as áreas de abrangência, sendo identificados as relações entre elas e as possíveis causas referentes à falta de estanqueidade. As manifestações patológicas foram classificadas segundo o grau de risco aos usuários, ao meio ambiente e ao patrimônio, tendo como base a norma do IBAPE (2012), sendo estes: Crítico; Médio; Mínimo.

Para a formulação das possíveis causas buscou-se evidências para a realização do diagnóstico, correlacionando o interior e o exterior da edificação, analisando as suas influências. Desta forma foram registrados os possíveis diagnósticos e contabilizado o percentual de incidências das manifestações patológicas através de gráficos e tabelas, analisando os graus de risco associados, afim que gerar prioridades para intervenções futuras.

\subsection{Caracterização do objeto de estudo}

O município de Cruz das Almas está localizado a 146 quilômetros de Salvador, capital do estado, possuindo um clima tropical quente úmido, onde os meses de março e agosto apresentam os índices pluviométricos mais altos e os meses de setembro e fevereiro os mais baixos. Porém, nos meses de menores índices pluviométricos permanece umidade é alta. A pluviosidade varia entre 900 e 1300 $\mathrm{mm}$, a temperatura média anual é de $24,5^{\circ} \mathrm{C}$ e umidade relativa de $80 \%$ (Lima Filho; Coelho Filho; Heinemann, 2013). O fato de ser uma cidade úmida favorece a presença de umidade nas edificações, conduzindo ao surgimento de um maior número de manifestações patológicas, particularmente naquelas edificações que apresentem fragilidade na sua estanqueidade, especialmente no que se refere a umidade descendente.

A estrutura do Pavilhão utilizado no estudo pode ser dividida em duas partes, conforme pode ser visto na Figura 1. A primeira parte é caracterizada pela edificação propriamente dita, composta por estrutura em concreto armado, com lajes pré-moldadas, alvenaria de vedação em bloco cerâmico e fachada revestida com revestimento cimentício e pintura. A laje superior da cobertura é protegida por telhas metálicas. A segunda parte é caracterizada por uma rampa de acesso que foi construída para dar acessibilidade ao pavimento superior. É uma estrutura mista composta por uma estrutura metálica, com lajes pré-moldadas e vedação em bloco cerâmico. A primeira parte está dividida em quatro Alas (A - térreo, B - térreo, $\mathrm{C}-1^{\circ}$ andar e $\mathrm{D}-1^{\circ}$ andar), contendo no total 27 laboratórios, 4 banheiros ( 2 no primeiro andar e 2 no térreo) e áreas de circulação como corredores, recepção e escadas (UFRB, 2019). Na Figura 2 é apresentada a fachada da edificação de estudo. 


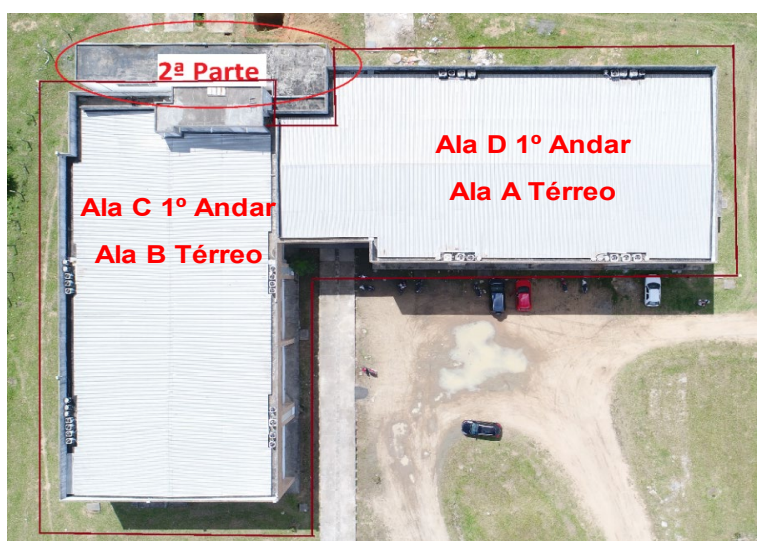

Figura 1 - Divisão da Estrutura do Pavilhão de Laboratórios

Fonte: O autor (2019).

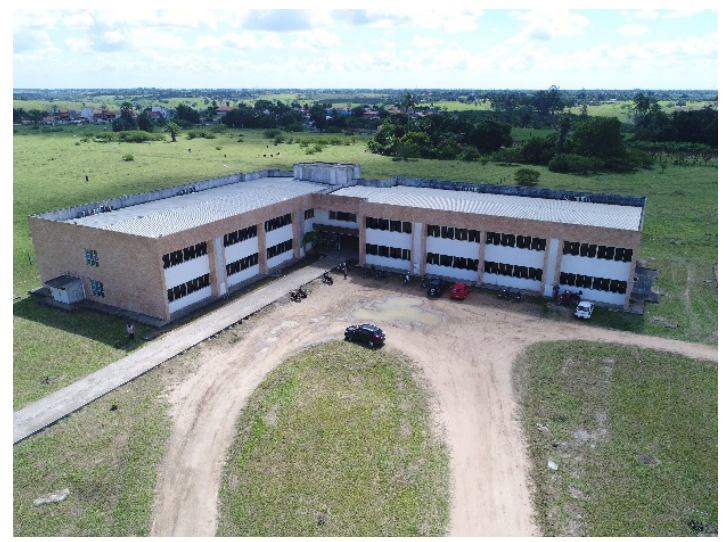

Figura 2 - Fachadas do Pavilhão de Laboratórios Fonte: O autor (2019).

\section{RESULTADOS E DISCUSSÃO}

Na Figura 3 são apresentados os percentuais das manifestações patológicas encontradas na edificação de estudo. No total foram identificadas 281 ocorrências relacionadas com o comprometimento da estanqueidade.

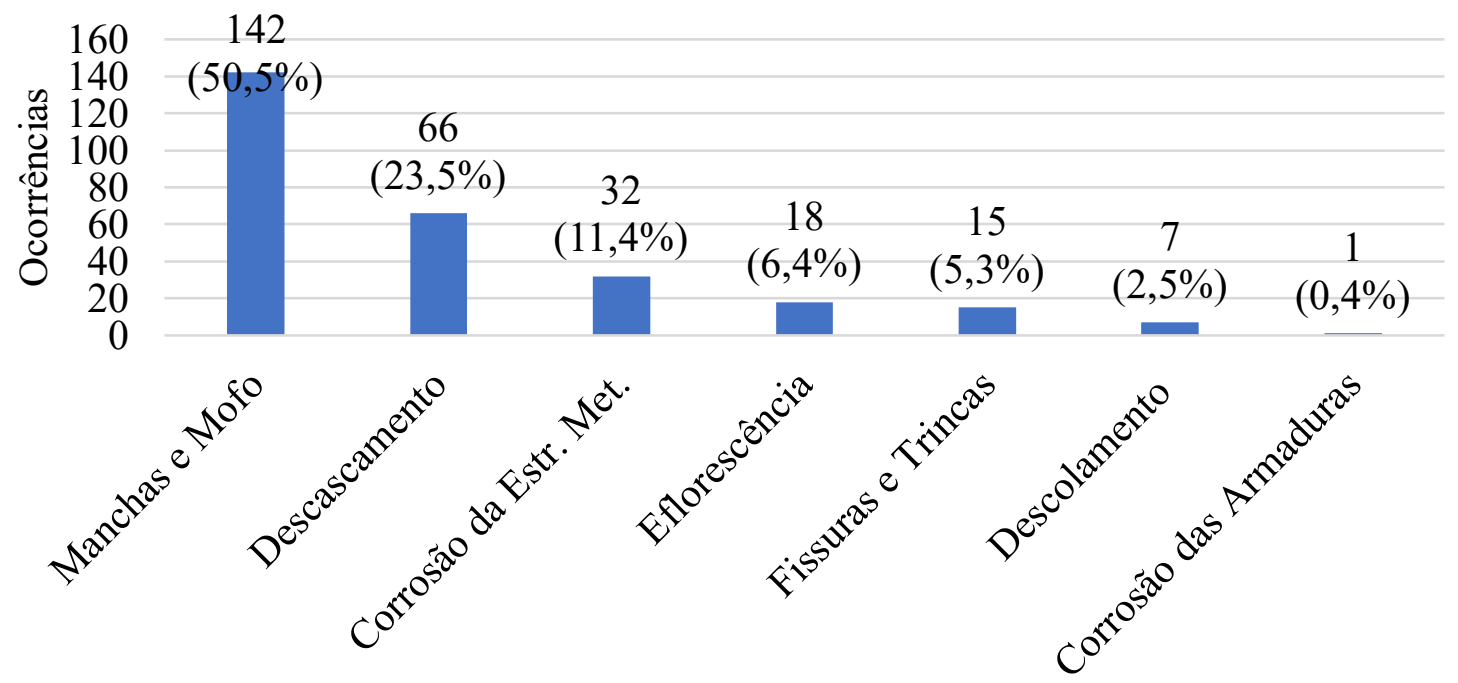

Manifestações Patológicas

- Ocorrências

Figura 3 - Ocorrências e Percentuais das Manifestações Patológicas.

É possível observar que das 281 ocorrências de manifestações, 50,5\% são do grupo de manchas e mofo, que em diversos casos teve sua presença associada ao descascamento das pinturas, presente em $23,5 \%$ das ocorrências, e a formação de fissuras e trincas, presentes em 5,3\%. As fissuras e trincas contabilizadas são somente aquelas que visualmente poderiam estar relacionadas com a umidade excessiva.

A maior ocorrência de manchas e mofo já era esperado, já que essas são as manifestações que indicam o primeiro indício da presença de umidade na edificação. Por outro lado, a corrosão de 
armaduras apareceu com um percentual menor de ocorrência. Este resultado também era esperado, já que a idade da construção é bastante recente ( 6 anos).

Na Figura 4 é possível demonstrar o caso de um dos laboratórios que está localizado na Ala C. Neste ambiente toda a lateral em contato com o meio externo apresenta manchas e descascamentos em estado avançado, além de apresentar infiltrações e vazamentos em vigas, pilares e forro.

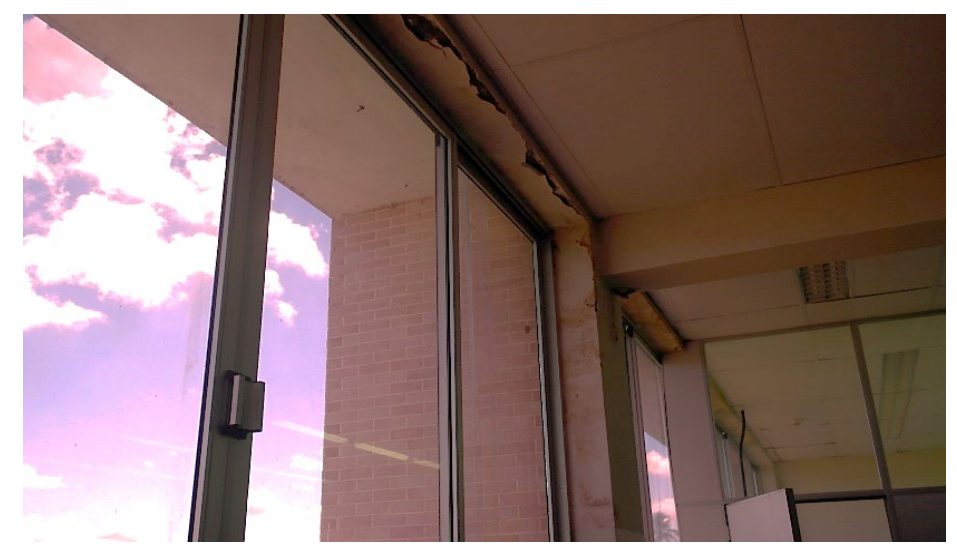

Figura 4 - Imagem da esquadria de um dos laboratórios da edificação.

Fonte: $\mathrm{O}$ autor (2019).

No Quadro 1 é apresentada uma síntese das ocorrências de manifestações patológicas distribuídas por localização na edificação, bem como os graus de risco atribuídos a cada uma delas. É possível constatar que a rampa de acesso é o local mais degradado da edificação, totalizando $26,7 \%$ das manifestações patológicas encontradas em toda a edificação, seguida pela fachada com 16,7\%, as alas C e D ( $1^{\circ}$ andar), com 16,4\% e 15,3\%, respectivamente, a áreas comuns com $12,5 \%$ ) e por fim, as alas do térreo, B, com 7,8\%, e A, com 4,6\%. Em relação aos graus de risco, percebe que 49,8\% das manifestações patológicas foi enquadrada com grau de risco mínimo, 27,8\% médio e 22,4\% mínimo. As manchas e mofo, que foram as manifestações mais recorrentes na edificação, apresentaram 82 ocorrências classificadas como grau mínimo, 35 como grau médio e 25 como grau crítico.

\begin{tabular}{|c|c|c|c|c|c|c|c|c|c|c|c|c|c|c|c|c|c|c|c|c|c|c|c|}
\hline \multirow{3}{*}{ LOCALIZAÇÃO } & \multicolumn{23}{|c|}{ OCORRÊNCIAS E GRAUS DE RISCOS DAS MANIFESTAÇÕES PATOLÓGICAS } \\
\hline & \multicolumn{3}{|c|}{$\begin{array}{c}\text { Fissuras e } \\
\text { Trincas }\end{array}$} & \multicolumn{3}{|c|}{$\begin{array}{c}\text { Manchas e } \\
\text { Mofo }\end{array}$} & \multicolumn{3}{|c|}{$\begin{array}{c}\text { Descascament } \\
\text { o }\end{array}$} & \multicolumn{3}{|c|}{ Descolamento } & \multicolumn{3}{|c|}{$\begin{array}{c}\text { Corrosão da } \\
\text { Estrutura } \\
\text { Metálica } \\
\end{array}$} & \multicolumn{3}{|c|}{$\begin{array}{c}\text { Corrosão das } \\
\text { Armaduras }\end{array}$} & \multicolumn{3}{|c|}{ Eflorescência } & \multicolumn{2}{|c|}{ TOTAL } \\
\hline & \begin{tabular}{|l|}
$\mathbf{C R}$ \\
\end{tabular} & ME & MI & CR & ME & MI & CR & ME & MI & CR & ME & MI & CR & ME & MI & CR & ME & MI & CR & ME & MI & Número & Percentual \\
\hline ALA A & & & & & 2 & 10 & & & & & & & & & & & & & & 1 & & 13 & 4,6 \\
\hline ALA B & & 1 & 5 & 1 & 4 & 5 & & 1 & 5 & & & & & & & & & & & & & 22 & 7,8 \\
\hline ALA C & 3 & & & 10 & 3 & 16 & 5 & & 8 & & & & & & & & & & & 1 & & 46 & 16,4 \\
\hline ALA D & & 1 & & 6 & 5 & 18 & & 4 & 9 & & & & & & & & & & & & & 43 & 15,3 \\
\hline ÁREAS COMUNS & & & 1 & 2 & 8 & 16 & & 2 & 4 & & & & & & & & & 1 & & & 1 & 35 & 12,5 \\
\hline RAMPA & & & & & 4 & 12 & 5 & 9 & 6 & & & & 19 & 13 & & & & & 3 & 2 & 2 & 75 & 26,7 \\
\hline FACHADA & & & 4 & 6 & 9 & 5 & & 3 & 5 & 2 & 2 & 3 & & & & & & & 1 & 3 & 4 & 47 & 16,7 \\
\hline PARCIAL & 3 & 2 & 10 & 25 & 35 & 82 & 10 & 19 & 37 & 2 & 2 & 3 & 19 & 13 & 0 & 0 & 0 & 1 & 4 & 7 & 7 & \multirow{2}{*}{281} & \multirow{2}{*}{100,0} \\
\hline TOTAL & \multicolumn{3}{|c|}{15} & \multicolumn{3}{|c|}{142} & \multicolumn{3}{|c|}{66} & \multicolumn{3}{|c|}{7} & \multicolumn{3}{|c|}{32} & \multicolumn{3}{|c|}{1} & \multicolumn{3}{|c|}{18} & & \\
\hline GRAUS DE RISCO & \multicolumn{9}{|c|}{ CRÍTICO (CR) } & \multicolumn{9}{|c|}{ MÉDIO (ME) } & \multicolumn{5}{|c|}{ MÍNIMO (MI) } \\
\hline \begin{tabular}{|l|} 
NÚMERO \\
\end{tabular} & \multicolumn{9}{|c|}{63} & \multicolumn{9}{|c|}{78} & \multicolumn{5}{|c|}{140} \\
\hline PERCENTUAL & \multicolumn{9}{|c|}{22,4} & \multicolumn{9}{|c|}{27,8} & \multicolumn{5}{|c|}{49,8} \\
\hline
\end{tabular}

Quadro 1 - Síntese das ocorrências e graus de riscos das manifestações patológicas Fonte: O autor (2019).

Na Figura 5 são apresentas as informações de como as manifestações patológicas estão distribuídas nos diferentes elementos construtivos. É possível perceber que as vigas, a parte superior da parede de vedação e a laje somam quase $70 \%$ das manifestações patológicas. Este resultado, analisado em 
concomitância com o Quadro 1, indica que a presença de umidade que está causando os processos de deterioração está associada com a vinda de água da cobertura, muito possivelmente causada por uma ineficiência da estanqueidade da laje e das telhas metálicas presentes. Considerando que a presença de umidade constante causa processos progressivos de deterioração, é possível esperar que as manifestações que foram classificadas com grau mínimo e médio acabem se agravando rapidamente, caso os problemas de estanqueidade da cobertura não sejam resolvidos imediatamente.

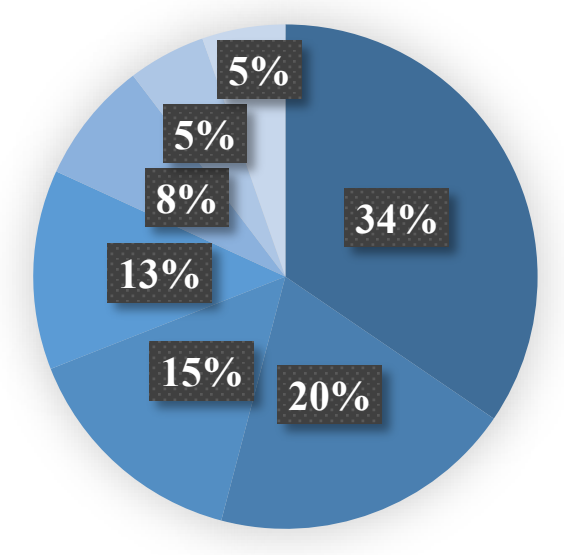

Viga

- Parte Superior Parede

Laje

Pilar

Meio da Parede

Pé de Parede

Peitoril

Figura 5 - Ocorrência em Elementos Construtivos

Fonte: $\mathrm{O}$ autor (2019).

As 75 ocorrências de manifestações patológicas na rampa de acesso estão relacionadas aos grupos de manchas e mofo, descascamento, corrosão da estrutura metálica e eflorescências causadas pela lixiviação do hidróxido de cálcio do concreto da laje, afetando em sua maioria vigas, lajes e parte superior das paredes. Entre as manifestações identificadas foi possível identificar um número considerável de graus crítico e médio, um exemplo de manifestações de grau crítico é a corrosão da estrutura metálica, que foi observada com perda significativa da seção de sua estrutura localizada na rampa. Devido ao estado de conservação da estrutura, a sua utilização foi interditada, presando pela segurança dos usuários. Através da Figura 6 é possível observar algumas dessas ocorrências indicando também eflorescências com formação de estalactites devido a umidade presente na laje pré-moldada.

De acordo com o projeto arquitetônico a rampa deveria possuir telhas metálicas, em sua cobertura, assim como na primeira parte do Pavilhão, porém desde o princípio a rampa encontra-se sem proteção em sua laje através da instalação de telhas metálicas. Além do fato de não haver uma cobertura adequada, é possível observar deficiências no sistema de as impermeabilização e vedação da parede, com acúmulo de água na cobertura e até presença de vegetação. A situação em que se encontra a cobertura da rampa é demonstrada na Figura 7. 


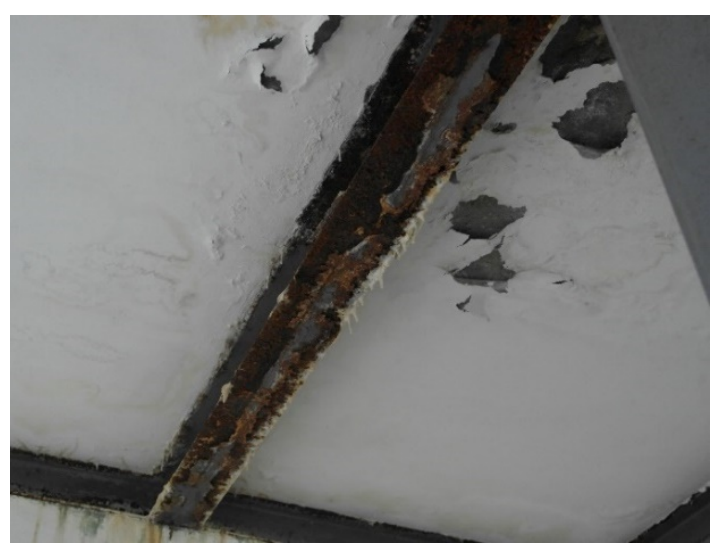

Figura 6 - Manifestações Patológicas em Rampa.

Fonte: O autor (2019).

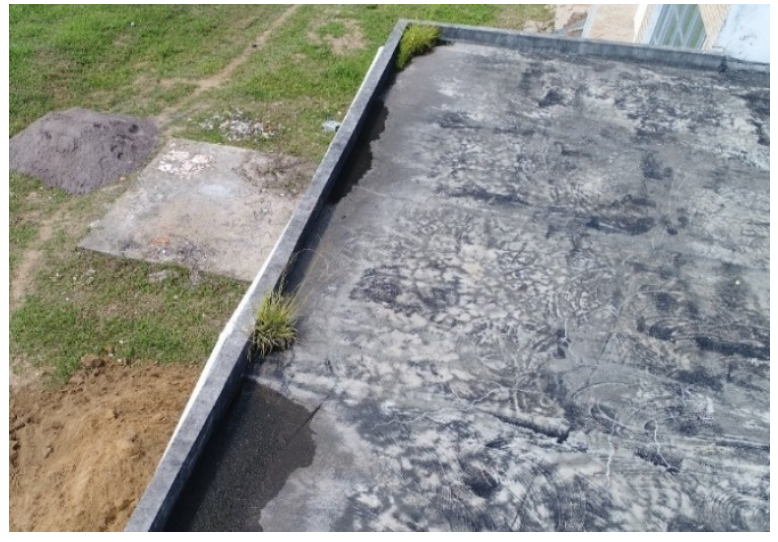

Figura 7 - Cobertura da Rampa. Fonte: O autor (2019).

A fachada apresenta 47 ocorrências que estão ligadas aos problemas de impermeabilização das calhas e a inexistência de pingadeiras. Em vários pontos da fachada é possível observar descolamentos e eflorescência, desde a situações de grau mínimo, até casos em que há comprometimento da coloração da cerâmica ou até mesmo quando não há mais revestimento. $\mathrm{Na}$ Figura 8 é apresentado um dos casos em relação ao descolamento presente na Ala C. De modo geral estão relacionados à fachada $10 \%$ das manifestações, dos quais são localizados $5 \%$ nos elementos peitoril e 5\% pé de parede, conforme pode ser visto na Figura 5. As ocorrências da Ala $\mathrm{B}$, zona da edificação que apresentou o segundo menor percentual, tem seus elementos localizados nas faces próximas à fachada com 22 ocorrências ao total.

Apesar de ser identificada apenas uma ocorrência durante a inspeção, foram observados indícios de corrosão como manchas marrom avermelhadas principalmente nas faces das lajes e vigas da fachada, porém não foi possível a confirmação somente com as imagens obtidas pelo drone. A exposição de armadura, indicando o estado inicial da corrosão, somente foi localizada em uma única situação em local que o cobrimento do concreto foi retirado para a passagem de eletrocalhas, conforme mostra a Figura 9. O aparecimento de Poliestireno Expandido (EPS) com manchas e mofos demonstraram a possibilidade de corrosões não visíveis.

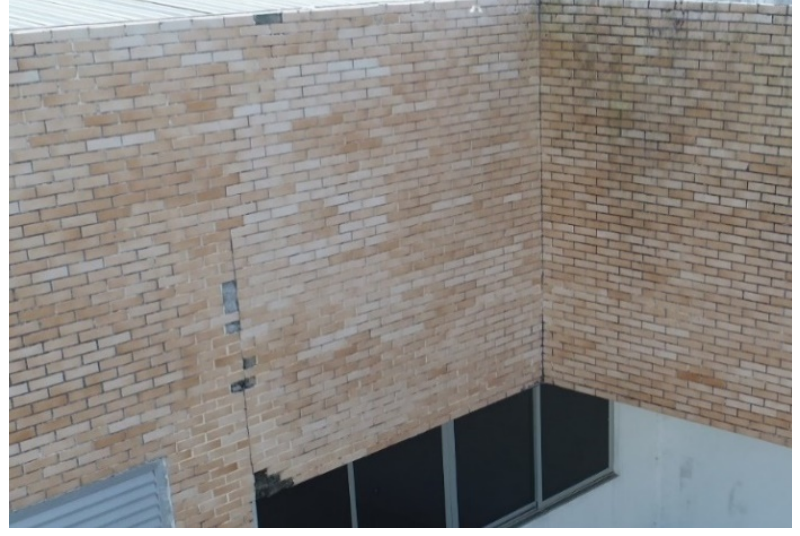

Figura 8 - Destacamento em Fachada Localizada na Ala C. Fonte: O autor (2019).

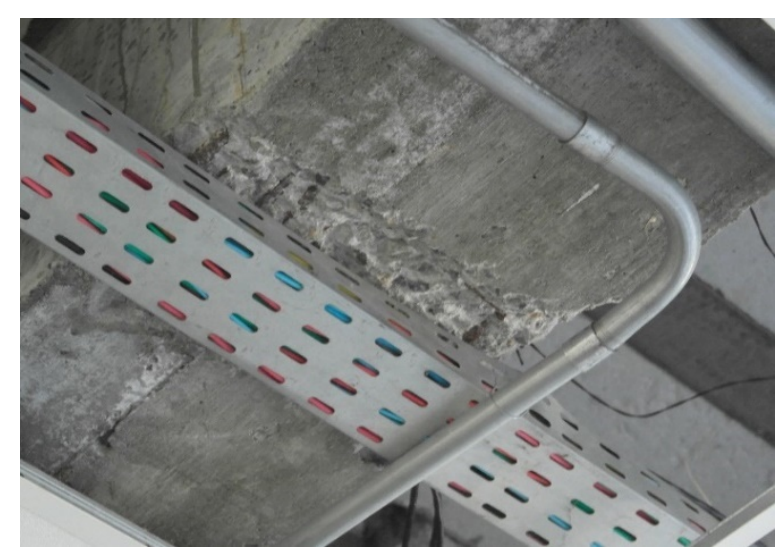

Figura 9 - Indícios de ocorrência de Corrosão de Armaduras.

Fonte: O autor (2019). 
Ao analisar os dois períodos de inspeção do interior da edificação observou-se que dos 27 (vinte e sete) laboratórios, 9 (nove) apresentaram vazamentos após os períodos de chuvas, comprovando que as manifestações patológicas estão relacionadas com um problema ainda existente de falta de estanqueidade. Inclusive, a maioria das manifestações desse ambiente estão classificadas em graus de risco médio e crítico. A presença da umidade acaba inutilizando parte dos laboratórios ou todo seu funcionamento, influenciando também os elementos de acabamentos como forro e piso.

Um dos laboratórios localizados na Ala $C$ apresenta os maiores problemas de falta de estanqueidade. Além de infiltrações em vigas e pilares, após as chuvas o ambiente apresentou poças de água no piso. Através da Figura 10 é possível observar poças no meio da sala, comprometendo totalmente a utilização do cômodo para a função projetada.

Considerando o maior número de manifestações patológicas nas Alas $(\mathrm{C}$ e D) do pavimento superior, é possível considerar que a ocorrências dos sintomas esteja associada a falhas na impermeabilização da laje da cobertura e no sistema pluvial. Na Figura 11 observa-se uma vista superior onde percebe-se a degradação da impermeabilização das calhas de concreto, com manchamento escurecido pela presença constante de umidade, como também manchas esbranquiçadas que poderiam estar sendo geradas pela lixiviação do hidróxido de cálcio.

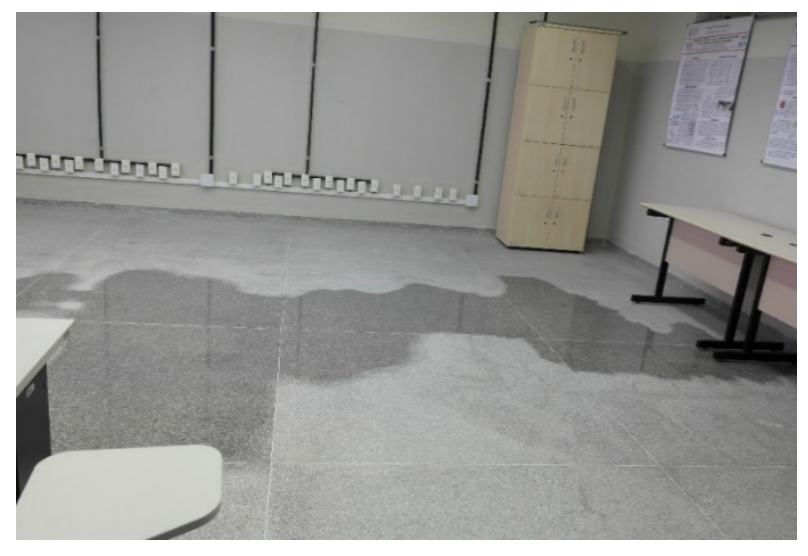

Figura 10 - Laboratório de Modelagem em Hidrologia e Recursos Hídricos. Fonte: O autor (2019).

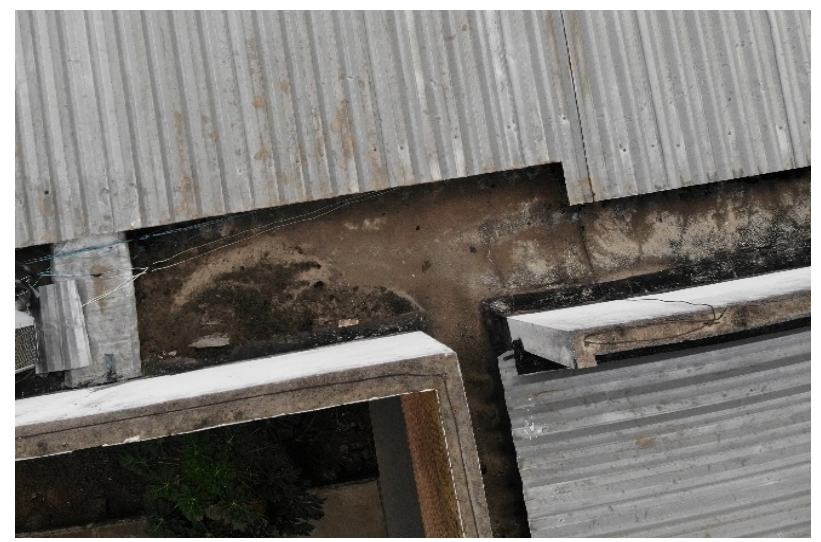

Figura 11 - Degradação da Impermeabilização das Calhas. Fonte: O autor (2019).

Problemas como o apresentado na Figura 11 foram localizados em toda a área superior a laje, sendo também identificado próximos aos rufos. Podem estar relacionados ao uso inadequado dos materiais para impermeabilização e falta de manutenção. Em todas as vigas localizadas abaixo dessas calhas e rufos foi possível identificar manifestações patológicas, muitas vezes classificados com grau crítico. O projeto mostra que a impermeabilização realizada nas calhas é do tipo membrana asfáltica, um tipo de impermeabilização flexível. Entretanto, é preciso considerar que estes elementos estão constantemente expostos às radiações solares, precisando estar associados com dispositivos para proteção mecânica e climática.

As alas C e D, áreas comuns e fachada apresentam maiores ocorrências em vigas, parte superior da parede, pilares e lajes. A ocorrências dos processos de deterioração podem estar sendo influenciados por desempenho inadequado da impermeabilização, sistema pluvial e cobertura. $\mathrm{Na}$ Figura 12 é apresentada uma zona da cobertura, onde é possível identificar acúmulos de água, deterioração da impermeabilização e deformações nas telhas metálicas. A cobertura tem grande influência na garantia da estanqueidade, evitando assim que a umidade descendente gere deterioração na edificação. Além de inadequada impermeabilização foram identificados acúmulos 
de água nas telhas metálicas indicando que não há a devida inclinação e direcionamento para o escoamento das águas pluviais, além de deformações e furos que permitem a passagem de água. Associado à instalação do ar-condicionado existe a presença dos shafts, onde são passadas as tubulações. Nestes espaços foram identificadas manifestações patológicas do tipo manchas, mofo e descascamento, justamente devido à presença constante de umidade. A falta de estanqueidade pode estar associada a perfuração da laje para passagem de tubulação, instalação de arcondicionado ou outros dispositivos, sem que tenha sido previsto o reparo da impermeabilização. Os usuários do espaço informaram que há certa de um ano, partes da cobertura da Ala D e os locais próximos aos shafts das instalações dos ar-condicionados sofreram intervenções, com aplicação de mantas asfálticas. Constataram que esta intervenção reduziu consequentemente as ocorrências da Ala A (térreo), localizada logo abaixo da Ala D. Entretanto, percebe-se, a partir da identificação de manchas de umidade que ainda existe infiltração no local das passagens de tubulações, conforme é possível ver na Figura 13.

A entrada de água descendente (precipitação) devido à falta de estanqueidade da cobertura também é refletida nos materiais do forro, que acabam se deteriorando. A não realização de manutenção nos forros intensifica a sua deterioração, provocando a perda da sua funcionalidade. Inclusive, identificou-se ausência de parte do forro em alguns laboratórios e zonas dos corredores.

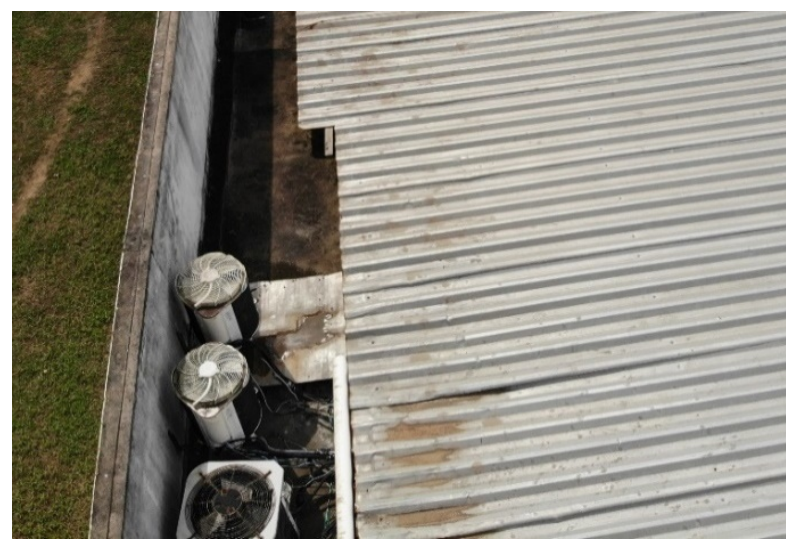

Figura 12 - Irregularidades nas telhas e zonas de instalação de ar-condicionado. Fonte: O autor (2019).

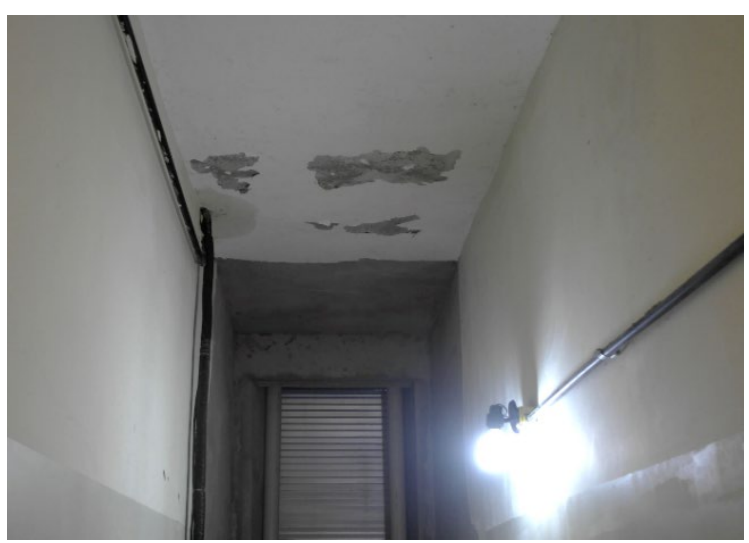

Figura 13 - Manchas de umidade na laje do shaft - Ala D. Fonte: O autor (2019).

\section{CONCLUSÃO}

Através do levantamento das manifestações patológicas foi possível concluir que as manchas e mofos foram as manifestações com maiores ocorrências e influenciaram todos os elementos construtivos analisados nessa pesquisa. $\mathrm{O}$ elemento construtivo com maior número de ocorrências foram as vigas, que estiveram ligadas a falta de estanqueidade da cobertura e fachada. Já a corrosão das armaduras foi a manifestação com menor ocorrência.

A realização das inspeções em três períodos diferentes permitiu a análise do comportamento da edificação referente ao seu desempenho frente a falta de estanqueidade da edificação. Os problemas de cobertura estão relacionados a deterioração da impermeabilização e a utilização de sistemas pluviais e de impermeabilização inadequados, além da falta de manutenção e vedação ineficiente das paredes, influenciando na constante degradação dos elementos construtivos que refletem no surgimento das manifestações patológicas. O comportamento em cadeia da degradação é observado devido as maiores consequências estarem relacionadas ao primeiro andar da edificação, com a 
presença de vazamentos e infiltrações que comprometem a habitabilidade, e o térreo possuir menores influências estando relacionadas à parte externa e vedação.

O grau de risco mínimo foi diagnosticado com maior frequência o que demonstra que a edificação vem dando sinais em relação a queda do desempenho, porém a falta de manuais e frequências nas manutenções acarretam a intensificação dessas manifestações. $O$ total de manifestações com graus médio e crítico somados está próximo ao total de grau mínimo o que demonstra o quão importante é observar os sinais das manifestações como pontos de vazamentos e forros danificados, afim de que se conheça as origens e sejam realizadas intervenções para que esses problemas não retornem. É possível concluir que a durabilidade do Pavilhão de Engenharias e seus sistemas está sendo comprometida com uma consequente redução da vida útil. A edificação não possui desempenho mínimo de utilização em função da falta de estanqueidade, o que gera processos de deterioração. Algo inesperado devido ao fato de que a edificação apresenta apenas 6 anos de uso.

Mesmo havendo erros executivos e utilização de materiais inadequados é de extrema importância para a edificação a existência de manuais e o cumprimento das suas orientações durante sua vida útil. Quando não há essa orientação são realizadas intervenções como as que ocorreram no pavilhão, solucionando apenas alguns problemas pontuais e não havendo solução da origem do problema em si. É preciso a realização de manutenção preventiva e corretiva afim preservar o desempenho de projeto, garantindo os requisitos da norma como a habitabilidade, além de reduzir os custos associados a manutenção e recuperação.

\section{AGRADECIMENTOS}

A Coordenadoria de Infraestrutura e Meio Ambiente - CIMAM da UFRB pelo fornecimento dos projetos arquitetônicos e estruturais que auxiliaram o levantamento de dados e a Universidade Federal do Recôncavo da Bahia (UFRB) por toda a estrutura disponibilizada.

\section{REFERÊNCIAS}

Associação Brasileira de Normas Técnicas. (1989). NBR 10844: Instalações Prediais de Águas Pluviais. Rio de Janeiro.

Associação Brasileira de Normas Técnicas. (2013). NBR 15575: Edifícios Habitacionais de até Cinco Pavimentos - Desempenho. Rio de Janeiro.

Cechinel, B. M. et al. (2007). "Infiltração em Alvenaria, estudo de caso em edifício na grande Florianópolis”. Caderno de publicações acadêmicas. Instituto Federal de Educação, Ciência e Tecnologia de Santa Cantarina - IF - SC.

Costa Junior, M. P.; Silva, M. G. (2003). A Influência do Processo Produtivo no Controle de Patologias e nos Processos de Manutenção. Revista Engenharia, Ciência e Tecnologia, v. 6, n. 4, 2003.

IBAPE - Instituro Brasileiro de Avaliações e Perícias de Engenharia. (2012). "Norma de Inspeção Predial Nacional”. São Paulo - SP.

Lichtenstein, N. B. (1986). Patologia das Construções Procedimento para Diagnóstico e Recuperação. Boletim Técnico do Departamento de Engenharia de Construção Civil. Escola Politécnica da Universidade de São Paulo, Cidade Universitária - SP.

Lima Filho, A. F.; Coelho Filho, M. A.; Heinemann, A. B. (2013). Determinação de épocas de semeadura do feijão caupi no Recôncavo Baiano através do modelo CROPGRO. Revista Brasileira de Engenharia Agrícola e Ambiental, v. 17, n. 12, p 1294-1300. 
Pina, G. L. (2013). “Patologia nas habitações populares”. Rio de Janeiro: Escola Politécnica da UFRJ, 2013.

Soares, F. F. (2014). A importância do Projeto de Impermeabilização em Obras de Construção Civil. Rio de Janeiro: Escola Politécnica da UFRJ.

Souza, M. F. (2008). Patologias Ocasionadas Pela Umidade Nas Edificações. Belo Horizonte: Escola de Engenharia da UFMG.

Souza, V. C. M.; RIPPER, T. (1998). Patologia, recuperação e reforço de estruturas de concreto. São Paulo: Pini.

Universidade Federal Do Recôncavo Da Bahia (UFRB). (2019). Infraestrutura Pavilhão de Engenharia.

Disponível em $<$ https://www.ufrb.edu.br/cetec/estruturaadministrativa/infraestrutura\#pavilhao-de-engenharia $>$ Acesso em abril de 2019.

Yazigi, W. (2009). A Técnica de edificar. 10. ed. São Paulo: Pini: SindusCon. 